\title{
Numerical investigation on turbulent forced convection and heat transfer characteristic in spirally semicircle-grooved tube
}

\author{
Pitak Promthaisong ${ }^{1}$, Amnart Boonloi ${ }^{2}$ and Withada Jedsadaratanachai ${ }^{{ }^{*}}$
}

\begin{abstract}
Turbulent forced convection and heat transfer structure in the spirally semicircle-grooved tube heat exchanger are numerically examined. The computational problem is solved by finite volume method (FVM) with the SIMPLE algorithm. The influences of groove depth and helical pitch on heat transfer, pressure loss, and thermal performance are investigated for turbulent regime, $R e=5000-20,000$. As a result, the swirling flow is found through the test section due to the groove on the tube wall. The flow structure in the spirally semicircle-grooved tube can separate into two types: main and secondary swirling flows. The main swirling flow is found in all cases, while the secondary swirling flow is detected when $D R \geq 0.06$. The swirling flow disturbs the thermal boundary layer on the tube wall that is an important reason for heat transfer augmentation. In range studies, the enhancements on heat transfer and friction loss are around 1.16-1.96 and 1.2-10.8 time above the smooth tube, respectively. The optimum thermal performance is around 1.11, which detected at $D R=0.06, P R=1.4$, and $R e=5000$. The correlations of the Nusselt number and friction factor for the spirally semicircle-grooved tube with $P R=1.4$ are produced to help to design the tube heat exchanger.
\end{abstract}

Keywords: Turbulent flow, Heat transfer, Pressure drop, Spirally semicircle-grooved tube

\section{Background}

Many types of heat exchangers, shell and tube heat exchanger, fin and tube heat exchanger, plate fin heat exchanger, etc., are used in various industries such as heat treatment process, chemical industry, power plant, automotive industry, food industry, etc. The heat exchangers had been improved with the main aims to augment the thermal performance and to reduce the size of the heat exchanger. The improvement techniques of the heat exchanger are divided into two types: active and passive techniques. The thermal performance improvement with the passive method is widely used more than the active mode due to it does not require the additional power into the heating system. The passive method is to use the turbulator or vortex generator such as fin, rib, baffle, wing, winglet, and roughness surface to generate the vortex flow or swirling flow in the heat exchanger that helps to increase the heat transfer rate and performance. The

\footnotetext{
* Correspondence: kjwithad@kmitl.ac.th

'Department of Mechanical Engineering, Faculty of Engineering, King Mongkut's Institute of Technology Ladkrabang, Bangkok 10520, Thailand Full list of author information is available at the end of the article
}

selection of the turbulator depends on the application of the heat exchanger. The roughness tube is a popular type of the vortex generator, which always use to enhance heat transfer rate and performance, due to it gives lower friction loss than the other types of the turbulators.

The performance improvement in the heat exchangers with the roughness surface had been investigated by many researches. For example, Lu et al. (2013a; 2013b) presented the convective heat transfer in a spirally grooved tube and transversely grooved tube as Fig. 1a, b, respectively. The spirally grooved tube with $e / D=0.0238,0.0306,0.0381$, and 0.0475 and the transversely grooved tube with $e / D=0.038$, 0.046 , and 0.092 were studied. Aroonrat et al. (2013) investigated the heat transfer in an internally grooved tube with constant wall heat flux. The internally grooved tube with the grooved depth, $e=0.2 \mathrm{~mm}$, grooved width, $w=0.2 \mathrm{~mm}$, and grooved pitch, $p=12.7,203,254$, and $305 \mathrm{~mm}$ was investigated. They found that the internally grooved tube provides the Nusselt number and friction factor higher than the smooth tube. The effects of the helically grooved tube on heat transfer and pressure drop of R-134a were experimentally studied by Laohalertdecha and Wongwises (2010). 


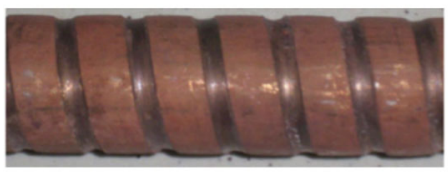

a spirally grooved tube [1]

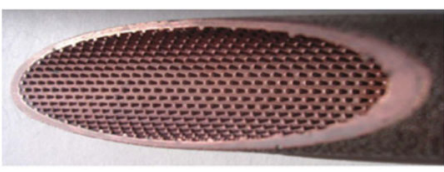

c roughness tube [10]

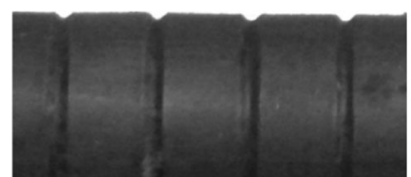

b transversely grooved tube [2]

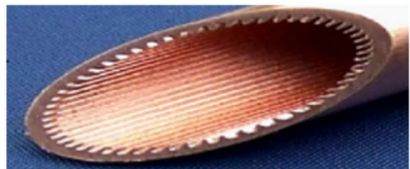

d Micro-groove fin-inside tubes [17]

Fig. 1 Geometries of the roughness tube from the published papers. a Spirally grooved tube (Lu et al. 2013a); b transversely grooved tube (Lu et al. 2013b); c roughness tube (Webb 2009); and d Micro-groove fin-inside tubes (Tang et al. 2007)

They studied with the grooved depth, $e=1.5 \mathrm{~mm}$ and grooved pitch, $p=5.08,6.35$ and $8.46 \mathrm{~mm}$. Their results show that the maximum heat transfer coefficient ratio and friction factor ratio up to $50 \%$ and $70 \%$ higher than the smooth tube, respectively. Khoeini et al. (2012) experimental investigated of $\mathrm{R}-134 \mathrm{a}$ on heat transfer in a corrugated tube with the depth of corrugation, $e=1.5 \mathrm{~mm}$ and pitch of corrugation, $p=8 \mathrm{~mm}$. They found that the corrugated tube has a significant effect on condensation heat transfer characteristic and provides the condensation heat transfer coefficient higher than smooth tube. The numerical study on turbulent flow and heat transfer enhancement in a rectangular grooved tube was reported by Liu et al. (2015). They found that the swirling flow, which induced by the grooved wall, leads to enhanced heat transfer. Al-Shamani et al. (2015) presented the heat transfer enhancement in a channel with a trapezoidal rib-groove in a turbulent region. They claimed that the channel with trapezoidal rib-groove can enhance heat transfer higher than smooth tube. The friction loss in a spirally internally ribbed tube with a vapor liquid two-phase was investigated by Cheng and Chen (2007). They stated that the friction loss in the spirally internally ribbed tube is around 1.6-2.7 times over the smooth tube. Hwang et al. (2003) presented the heat transfer and pressure drop in an enhanced titanium tube on turbulent region. The four types of the roughness tube were studied. They found that the thermal performance for using the roughness tube is higher than the smooth tube. Webb (2009) studied the heat transfer and friction loss in a threedimensional roughness tube (see Fig. 1c). Webb (2009) concluded that the roughness tube in the range studied provides the highest Nusselt number 3.74 times over the smooth tube. The comparison between the carbon steel smooth tube and spirally fluted tube on heat transfer characteristics was investigated by Wang et al. (2000). The experimental results show that the total heat transfer coefficient of the carbon steel spirally fluted tube is around 10-17 \% higher than the carbon steel smooth tube. Dong et al. (2001) presented the experimental studied the turbulent flow in a spirally corrugated tube on pressure drop and heat transfer. The roughness height ratio, $e / D=$ $0.0243,0.0199,0.0302$, and 0.0398 and spiral pitch ratio $p /$ $D=0.623,0.62,0.438,0.598$ were investigated. The spirally corrugated tube gives the heat transfer coefficient and the friction factor around 30-120\% and 60-160\% when compared with the smooth tube. The heat transfer and pressure drop during condensation of refrigerant 134a were studied in an axially grooved tube by Graham et al. (1999). They summarized that the axially grooved tube performs heat transfer rate better than smooth tube. The experimental investigation of a vertical tube with internal helical ribs on heat transfer was presented by Zhang et al. (2015). They concluded that the heat transfer coefficient for using the vertical tube with internal helical ribs is around 1.41 times higher than the smooth tube. Dizaji et al. (2015) reported the experimental investigation on heat transfer and pressure drop on turbulent flow in a corrugated tube. The four types of the corrugated tube were investigated. They stated that the inner tube provides the Nusselt number and friction factor about 10-52 \% and 150-190\%, respectively, over the smooth tube. Zhang et al. (2015) presented the effect of an internally grooved tube on heat transfer enhancement and pressure drop for using R417A. Their results indicated that the grooved tube in the range studied gave the maximum heat transfer performance and pressure drop about 2.8 and 2.6 times, respectively, above the smooth tube. Tang et al. (2007) used the roughness tube (see Fig. 1d) to study an oil-filled high-speed spinning process. Aroonrat and Wongwises (2011) studied the evaporation heat transfer characteristic and friction loss of $\mathrm{R}-134 \mathrm{a}$ in a vertical corrugated tube. They pointed out that the heat transfer and two-phase friction factor for using the corrugated tube are around $0-10 \%$ and $70-140 \%$, respectively, when compared with the base case. Liu et al. (2013) investigated the flow behavior and heat transfer characteristic in shell and tube heat exchanger for using a helical baffled cooler with a spirally corrugated tube. The results show that the Nusselt number increases around 60-130\% over the smooth tube 
on the tube side. Chen et al. (2013) presented the experimental investigation on the effect of a transversally corrugated tube for heat transfer and pressure drop with molten salt. The corrugated tubes with $e / D=0.034,0.047$ and $p / D$ $=0.31,0.57,1$ were investigated. They showed that the transversally corrugated tube gives the heat transfer and pressure drop grater that the smooth tube.

Most of previous researches, the heat transfer enhancement in the spirally grooved tube had been studied with the experimental method. In the present work, the heat transfer and flow structure in the spirally semicircle-grooved tube are investigated numerically. The numerical analysis can describe the flow configuration and heat transfer characteristic in the tube heat exchanger. The understanding on the mechanisms of flow and heat transfer is an important way to improve the thermal performance of the heat exchanger. The effects of groove depth in term of depth ratio $(D R=e / D)$ and helical pitch length $(P R=p / D)$ are considered for the turbulent regime, $R e=5000-20,000$.

\section{Physical geometry and computational domain}

The geometries and computational domain for the spirally semicircle-grooved tube are shown in Fig. 2. In the present study, the spirally semicircle-grooved tube is investigated with different helical pitch ratios, $p / D, P R=$ $0.6,0.8,1.0,1.2,1.4,1.6,1.8$, and 2.0 and depth ratios, $d /$ $D$ or $D R=0.02,0.04,0.06,0.08$, and 0.10 . The characteristic diameter of tube, $D$, is fixed around $0.05 \mathrm{~m}$, while the Reynolds numbers, Re, ranging from 5000 to 20,000.

The tetrahedral mesh is selected for the computational domain of the spirally semicircle-grooved tube. At the near wall region, grids have high density based on the gradients of temperature, pressure, and velocity, which the first near-wall cell next to the wall which is determined by the Reynolds number and satisfies $y^{+} \approx 1$.

\section{Assumption and boundary condition}

The inlet and outlet of the computational domain are set to be periodic boundary. No-slip wall condition is applied for the tube wall. The uniform heat flux around $600 \mathrm{~W} / \mathrm{m}^{2}$ is adopted for the heating wall. Air as the working fluid flows into the test section with the uniform mass flow rate at $300 \mathrm{~K}(\mathrm{Pr}=0.707)$. The thermodynamic properties of the air are assumed to be constant at mean bulk temperature. The forced convection heat transfer is considered, while the natural convection and radiation heat transfer are disregarded. The body force and viscous dissipation are ignored.

\section{Mathematical foundation and numerical method}

The incompressible turbulent flow with steady operation in three dimensions and heat transfer characteristic in the spirally semicircle-grooved tube are governed by the continuity equation, the Navier-Stokes equation, and energy equation. The realizable $k-\varepsilon$ turbulent model (Launder and Spalding 1974) is used for the present investigation.

$$
\begin{aligned}
\frac{\partial(\rho k)}{\partial t}+\frac{\partial\left(\rho k u_{j}\right)}{\partial x_{j}}= & \frac{\partial}{\partial x_{j}}\left[\left(\mu+\frac{\mu_{t}}{\sigma_{k}}\right) \frac{\partial k}{\partial x_{j}}\right]+G_{k} \\
& +G_{b}+\rho \varepsilon-Y_{m}+S_{k}
\end{aligned}
$$

and

$$
\begin{aligned}
\frac{\partial(\rho \varepsilon)}{\partial t}+\frac{\partial\left(\rho \varepsilon u_{j}\right)}{\partial x_{j}}= & \frac{\partial}{\partial x_{j}}\left[\left(\mu+\frac{\mu_{t}}{\sigma_{\varepsilon}}\right) \frac{\partial \varepsilon}{\partial x_{j}}\right] \\
& +\rho C_{1} S \varepsilon-\rho C_{2} \frac{\varepsilon^{2}}{k+\sqrt{v \varepsilon}} \\
& +C_{1 \varepsilon} \frac{\varepsilon}{k} C_{3 \varepsilon} G_{b}+S_{\varepsilon}
\end{aligned}
$$

where

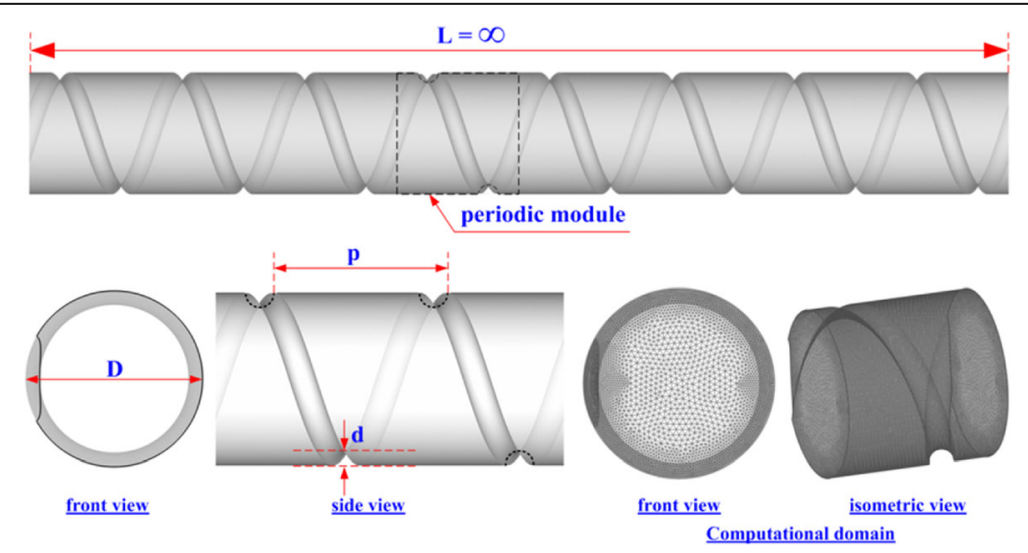

Fig. 2 Spirally semicircle-grooved tube geometries and computational domain 


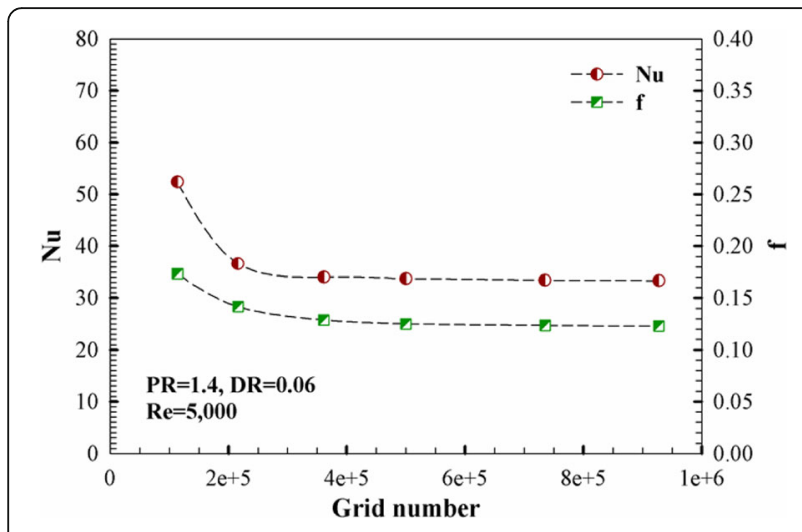

Fig. 3 Comparison of the grid number

$$
\begin{aligned}
C_{1} & =\max \left[0.43, \frac{\eta}{\eta+5}\right], \eta=S \frac{k}{\varepsilon}, S \\
& =\sqrt{2 S_{i j}} S_{i j}, S_{i j}=\frac{1}{2}\left(\frac{\partial u_{j}}{\partial x_{i}}+\frac{\partial u_{i}}{\partial x_{j}}\right)
\end{aligned}
$$

the constants in the model are given as follows:

$$
\sigma_{k}=1.0, \sigma_{\varepsilon}=1.2, C_{1 \varepsilon}=1.44, C_{2}=1.9
$$

where $S_{k}$ and $S_{\varepsilon}$ are user-defined source terms, $\sigma_{k}$ and $\sigma_{\varepsilon}$ are the turbulent Prandtl numbers for $k$ and $\varepsilon$, respectively.

For the convection terms, the SIMPLE algorithm for handling the pressure-velocity coupling and the QUICK scheme are solved using a finite volume approach (Patankar 1980). The energy equation is considered to be converged when the normalized residual values are less than $10^{-9}$ while the other variables are less than $10^{-5}$.

In the present study, to analyze the flow behavior and heat transfer characteristics, the Reynolds number, friction factor, Nusselt number, and thermal enhancement factor are the most important parameters, which can be written as follows:

The Reynolds number is calculated as follows:

$$
R e=\frac{\rho u_{0} D_{h}}{\mu}
$$

The friction factor is defined as

$$
f=\frac{(\Delta P / L) D_{\mathrm{h}}}{2 \rho \bar{u}^{2}}
$$

where $\Delta P$ is the pressure drop, $D_{\mathrm{h}}$ is the hydraulic diameter, and $u$ is mean flow velocity.

The local Nusselt number is given by

$$
N u_{x}=\frac{h_{x} D_{h}}{k}
$$

where $h$ is the convective heat transfer coefficient and $k$ the thermal conductivity.

The average Nusselt number can be obtained by

$$
N u=\frac{1}{A} \int N u_{x} d A
$$

Thermal performance enhancement factor (TEF) is defined as the ratio of the heat transfer coefficient of an augmented surface, $h$, to that of a smooth surface, $h_{0}$, under the constant pumping power condition. TEF can be calculated from

$$
\mathrm{TEF}=\left.\frac{h}{h_{0}}\right|_{p p}=\left.\frac{N u}{N u_{0}}\right|_{p p}=\left(\frac{N u}{N u_{0}}\right) /\left(\frac{f}{f_{0}}\right)^{1 / 3}
$$

where, $f_{O}$ and $N u_{O}$ are the friction factor and the Nusselt number of the smooth tube, respectively.

\section{Numerical validation}

The grid numbers around 113803, 216084, 361257, 500146, 735175, and 927547 for the spirally semicirclegrooved tube at $P R=1.4, D R=0.06$, and $R e=5000$ are compared as shown in Fig. 3. Under similar conditions, the values of the Nusselt number and friction factor rarely change when increasing grid cell from 500146 to 927547. Therefore, the grid around 500146 is used in all
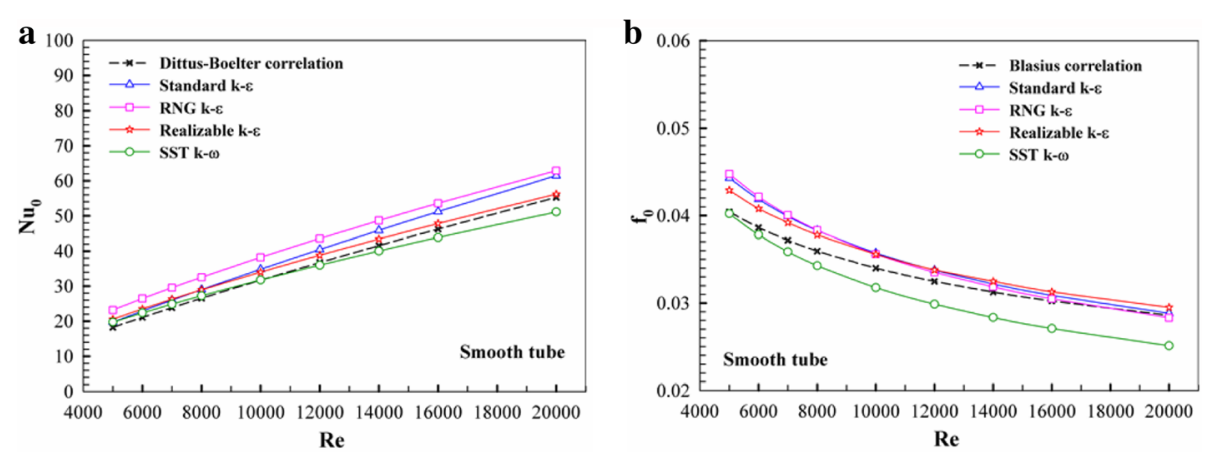

Fig. 4 Comparison of the turbulent model with correlation for $\mathbf{a}$ Nusselt number and $\mathbf{b}$ friction factor 

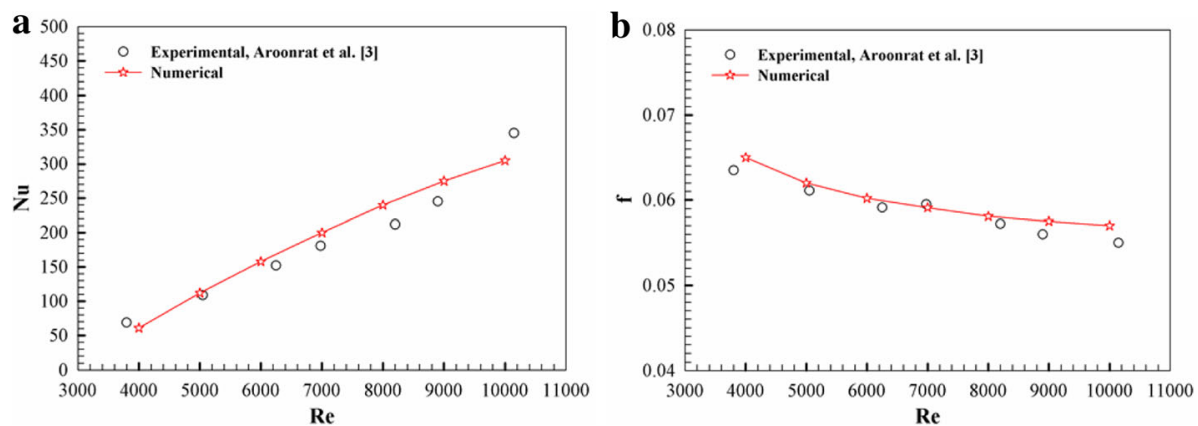

Fig. 5 Comparison of the numerical results with experimental results for a Nusselt number and $\mathbf{b}$ friction factor

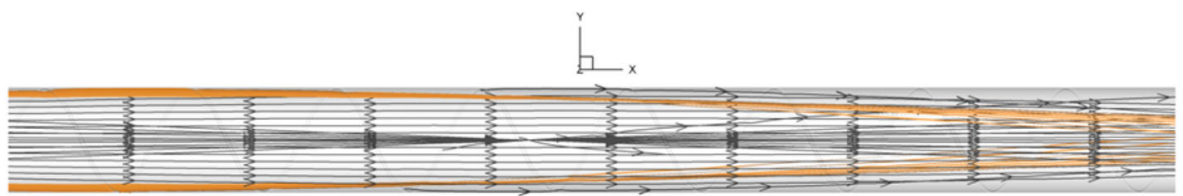

a

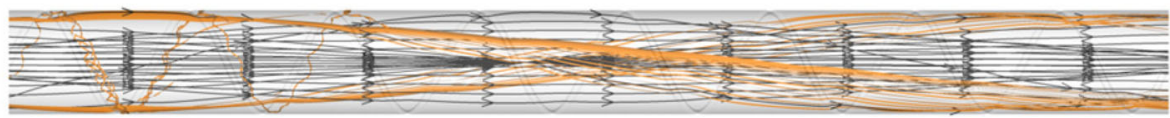

b

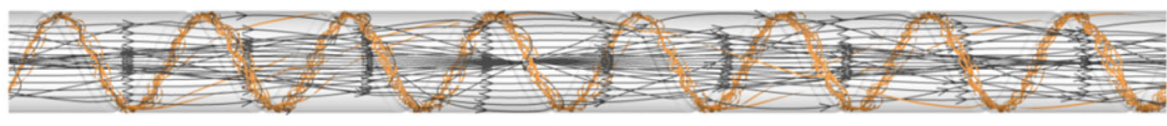

c

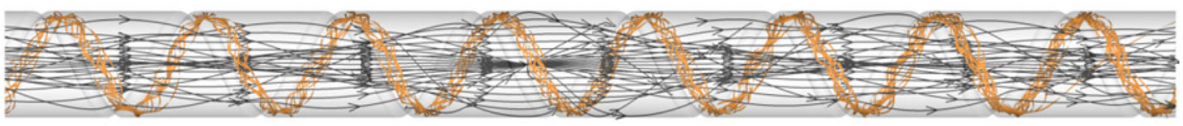

d

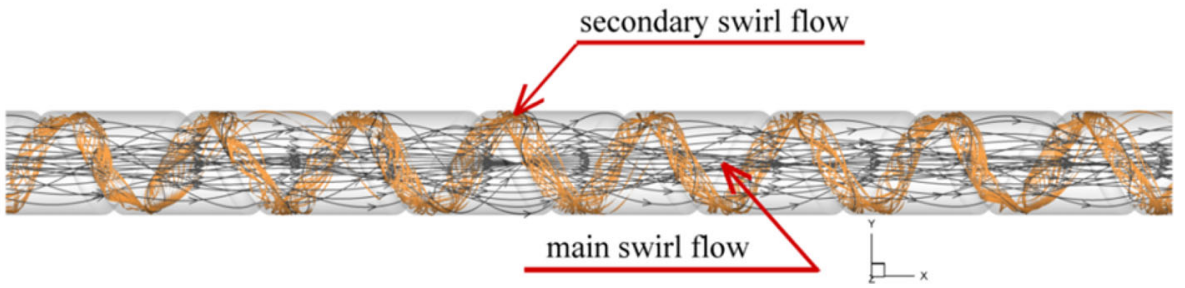

Side view

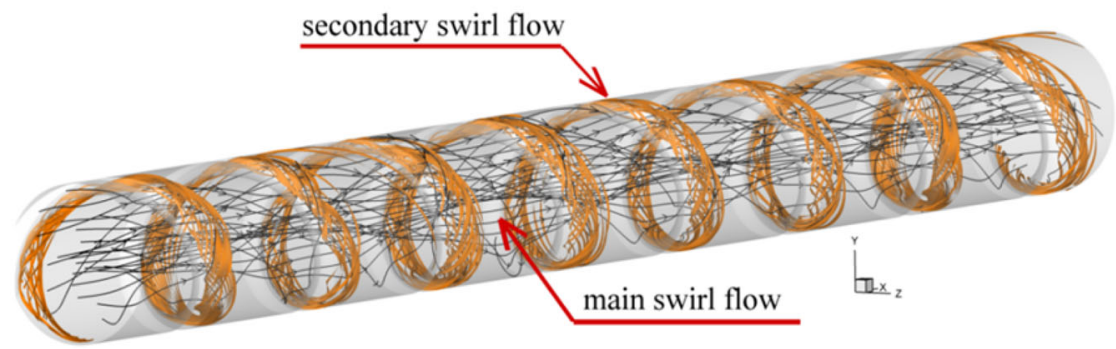

Isometric view

e

Fig. 6 Flow structure in axial flow for a $D R=0.02$, b $D R=0.04, \mathbf{c} D R=0.06, \mathbf{d} D R=0.08$, and $\mathbf{e} D R=0.10$ at $P R=1.4$ and $R e=5000$ of the spirally semicircle-grooved tube 
cases of the computational domain for the spirally semicircle-grooved tube.

The comparisons of the turbulence models, the Standard $k-\varepsilon$ turbulent model, the renormalized group (RNG) $k-\varepsilon$ turbulent model, the realizable $k-\varepsilon$ turbulent model, and the shear stress transport (SST) $k-\omega$ turbulent model and correlations (Incropera and Dewitt 2006) on the Nusselt number and friction factor of the smooth tube are shown in Fig. 4a, b, respectively. The numerical results show that the use of the realizable $k-\varepsilon$ turbulent model provides the excellent solutions with the values from the correlations. The realizable $k-\varepsilon$ turbulent model gives relative errors within 10.1 and $6.3 \%$ for the Nusselt number and friction factor, respectively.
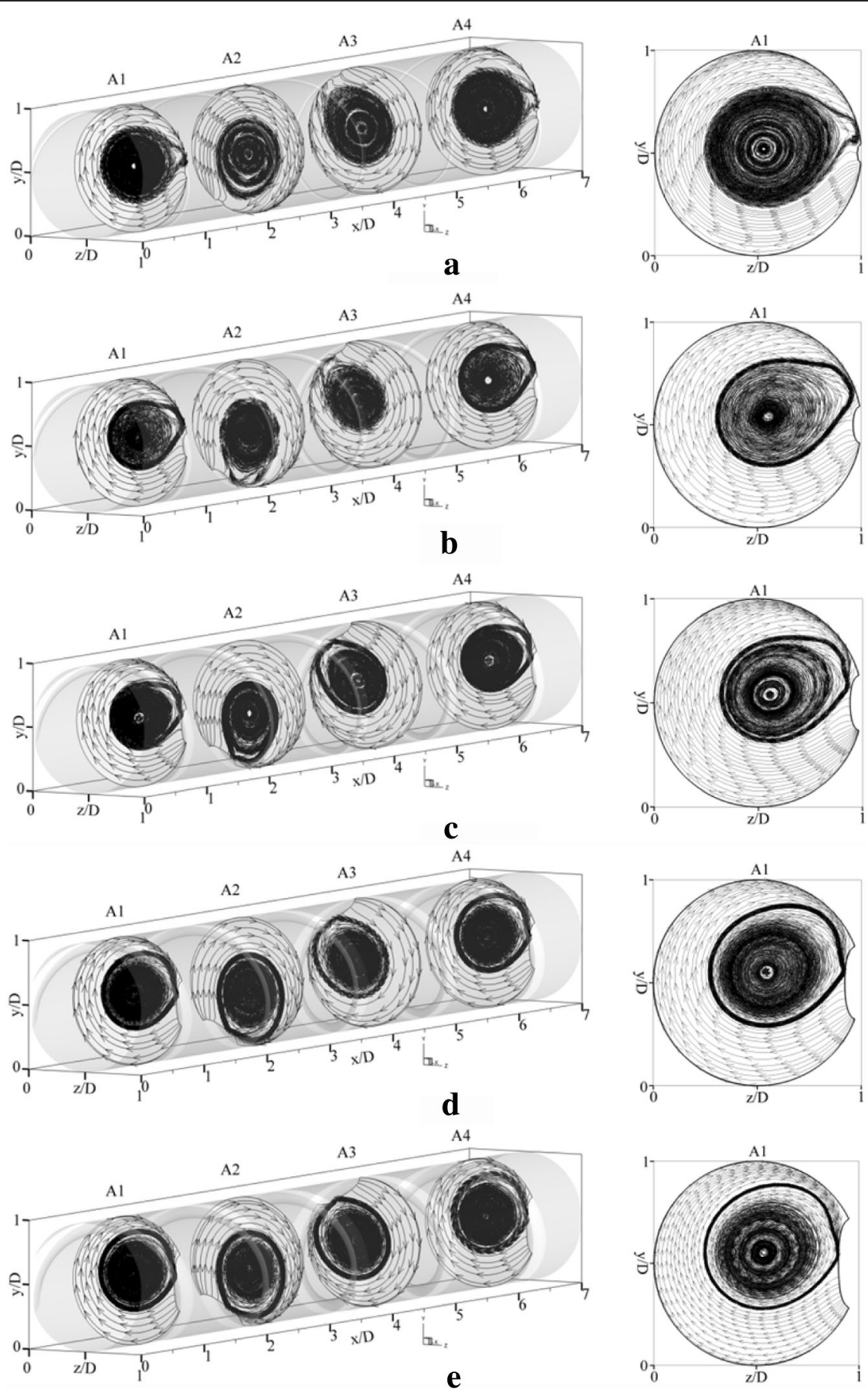

Fig. 7 Streamline in transverse planes for $\mathbf{a} D R=0.02$, b $D R=0.04, \mathbf{c} D R=0.06, \mathbf{d} D R=0.08$, and $\mathbf{e} D R=0.10$ at $P R=1.4$ and $R e=5000$ of the spirally semicircle-grooved tube 
Figure 5 presents the comparison of the numerical results with experimental results (Aroonrat et al. 2013) for using the realizable $k-\varepsilon$ turbulent model in the case of the spirally grooved tube with $e / D_{i}=0.028, w / D_{i}=0.028$, and $p / D_{i}=1.78$. In the figure, the deviations around 5.15 and $2.03 \%$ for the Nusselt number and friction factor, respectively, are detected. As a result in this part, it can be concluded that the computation domain of the spirally semicircle-grooved tube has the reliability to predict the flow, heat transfer, and thermal performance.

\section{Numerical result and discussion}

The numerical results in the spirally semicircle-grooved tube with various $D R$ s and $P R$ s are separated into four parts: flow configuration, heat transfer characteristics, thermal performance evaluation, and correlation.

\section{Flow configuration}

The longitudinal vortex flow and streamlines in cross sectional plane are selected to describe the flow pattern in the spirally semicircle-grooved tube. Fig. 6a-e presents the longitudinal vortex flow through the test section of the spirally semicircle-grooved tube at $P R$ $=1.4$ and $R e=5000$ for $D R=0.02,0.04,0.06,0.08$, and 0.1 , respectively. In general, the generation of the longitudinal vortex flow or swirling flow is due to the groove on the tube wall. As the figure shows, the flow structure can be divided into two types: main and secondary swirling flows. The main swirling flow is found at the core of the test tube, while the secondary swirling flow is detected on the groove surface (see Fig. 6e). The $D R=0.02$ and 0.04 produce the main swirling flow through the test section but not generate the secondary swirling flow on the groove surface, while the $D R=0.06,0.08$ and 0.1 can induce on both main and secondary swirling flows through the tube heat exchanger. This is because the depth of the groove on the tube heat exchanger is an important factor to create the vortex flow. Moreover, the groove depth effects for the strength or intensity of the swirling flow. The $D R=0.1$ provides the highest strength of the swirling flow, while the $D R=0.02$ gives the opposite result. The creation of the swirling flow is a disturbance of the thermal boundary layer
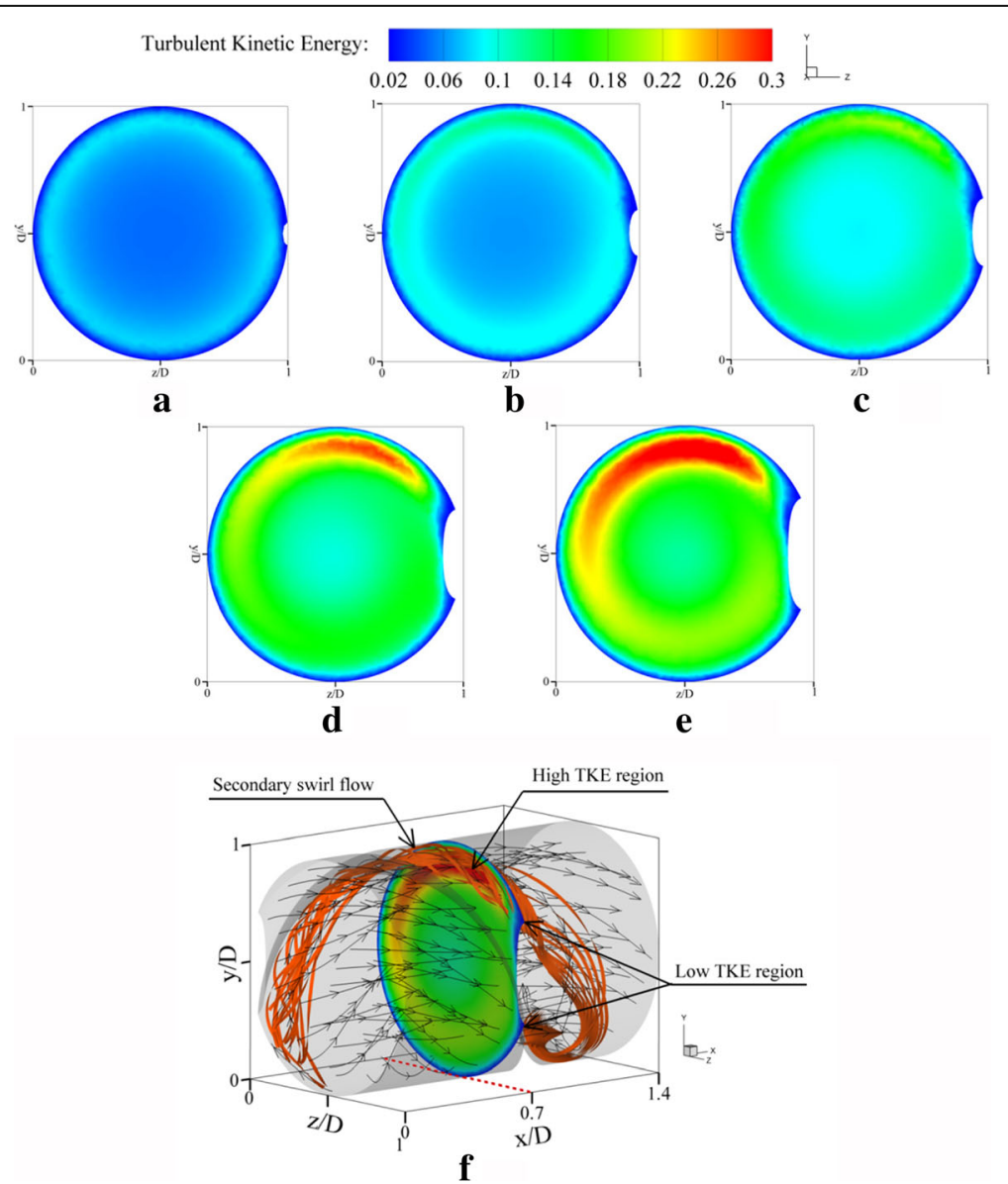

Fig. 8 Turbulent kinetic energy distribution in transverse planes for a $D R=0.02, \mathbf{b} D R=0.04, \mathbf{c} D R=0.06, \mathbf{d} D R=0.08$, e $D R=0.10$, and $\mathbf{f}$ isometric view of the $D R=0.10$ at $P R=1.4$ and $R e=5000$ of the spirally semicircle-grooved tube 


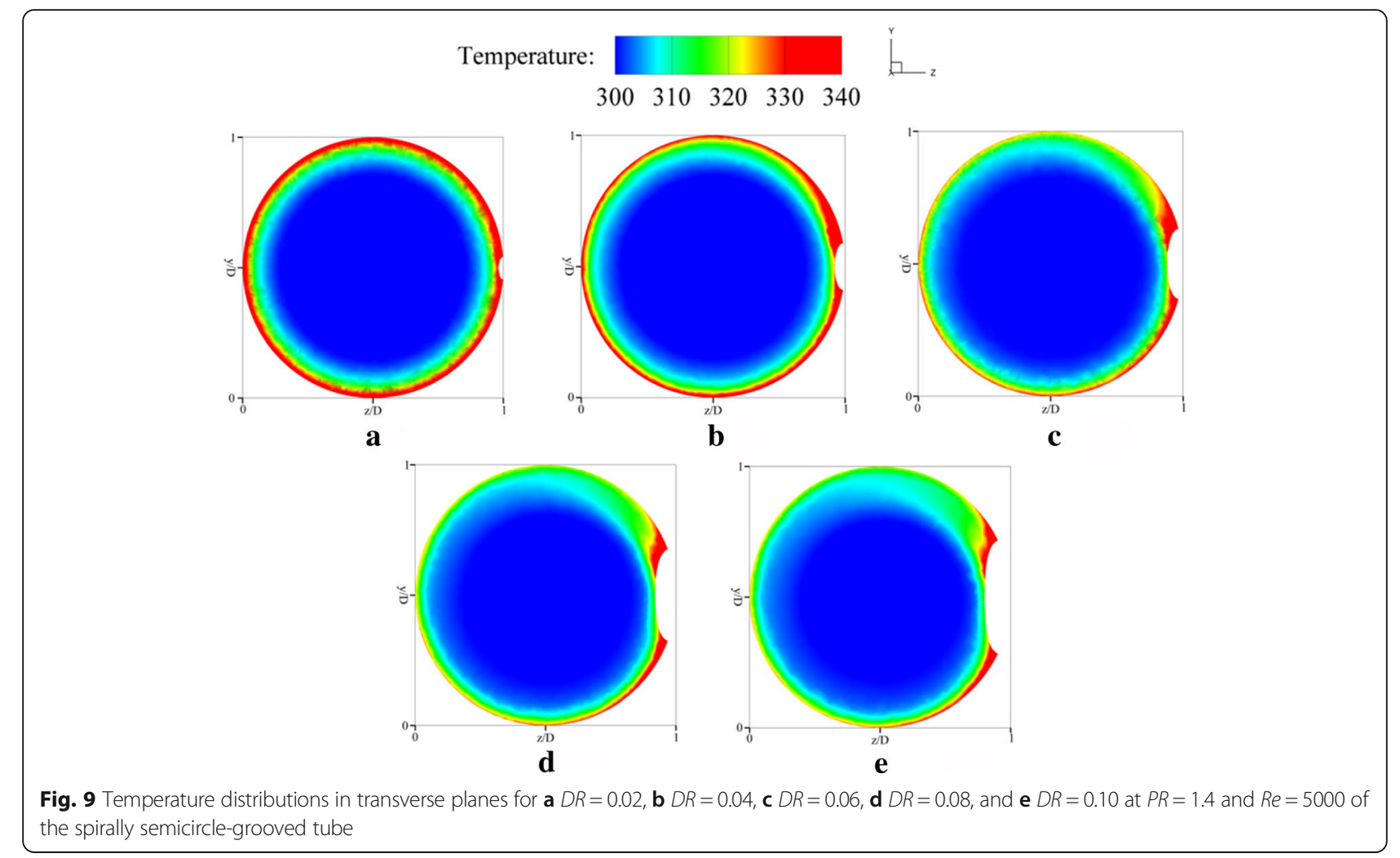

on the heating wall of the tube heat exchanger, especially, secondary swirling flow. The disturbance of the thermal boundary layer leads to enhanced heat transfer rate and thermal performance in the heating tube. The rising strength of the swirling flow may increase the intensity of the disturbance that a main reason for augmenting heat transfer rate.

Figure $7 \mathrm{a}-\mathrm{e}$ shows the streamlines in transverse plane of the spirally semicircle-grooved tube with $P R=1.4$ and $R e=5000$ for $D R=0.02,0.04,0.06,0.08$, and 0.1 , respectively. Generally, the vortex flows are found in all cases of the spirally semicircle-grooved tube. The pattern of the vortex flow at various $D R$ s is found similarly, but the strength of the vortex flow is not equal. The strength of the vortex flow is considered from the turbulent kinetic energy (TKE) distributions in transverse plane as depicted in Fig. 8a-e, for $D R=0.02,0.04,0.06,0.08$, and 0.1 , respectively, at $P R=1.4$ and $R e=5000$. The low TKE distribution is shown with blue contour, while the high TKE value is presented by red contour. The low TKE value is found at the edges of the groove, while the high TKE value is detected at the upper curve of the plane. The highest TKE distribution is found in case of $D R=$ 0.1 due to the highest vortex strength. Moreover, it is found that the TKE distribution directly relates with the secondary swirling flow (see Fig. 8e); therefore, the high TKE is not found in case of $D R=0.02$ and 0.04 due to the secondary swirling flow is not created.

\section{Heat transfer characteristic}

The heat transfer analysis in the spirally semicircle-grooved tube is described in terms of temperature contours and local Nusselt number distributions on the tube wall. Figure $9 \mathrm{a}-\mathrm{e}$ shows the temperature distributions in $y$ - $z$ planes of the spirally semicircle-grooved tube at $P R=1.4$ and $R e=$ 5000 for $D R=0.02,0.04,0.06,0.08$, and 0.1 , respectively. The high temperature is presented with red layer, while the opposite trend is depicted with blue contour. The high temperature is found in a large area at $D R=0.02$ due to the

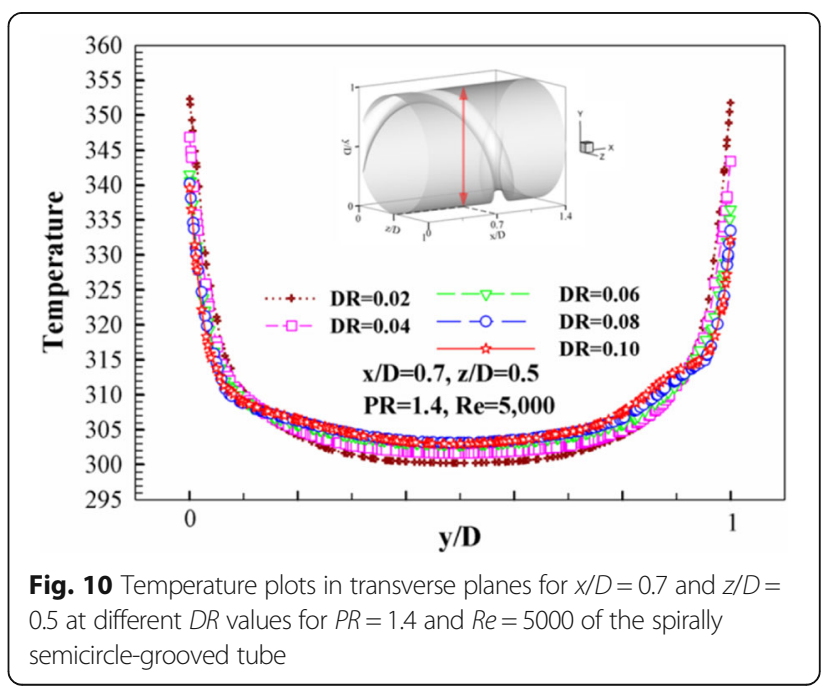



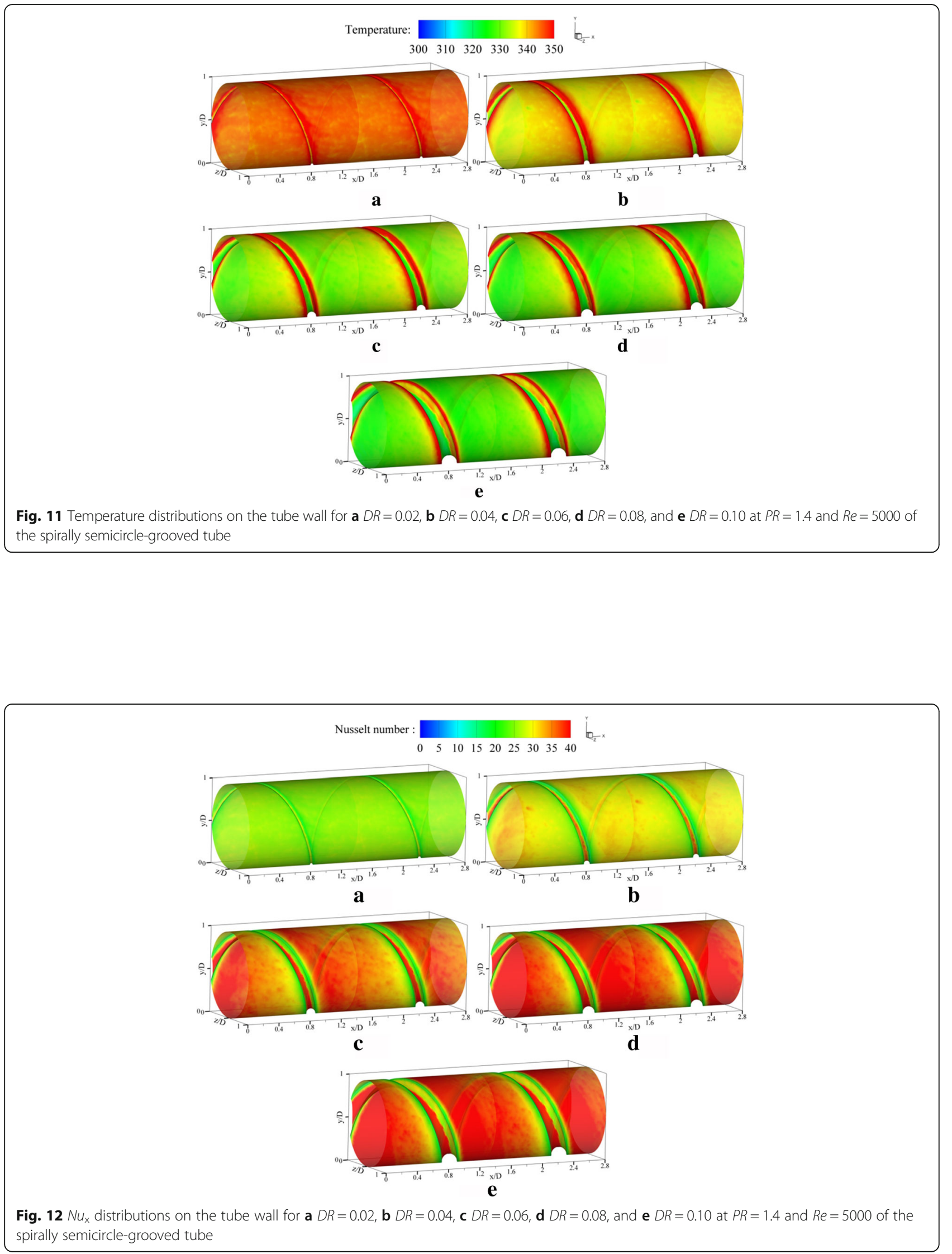
poor heat transfer rate, while the reverse trend is detected at $D R=0.1$. It can be concluded that the swirling flow and strength of the flow in the test tube has directly effect for heat transfer enhancement.

Figure 10 presents the plots of the temperature (at $x /$ $D=0.7$ and $z / D=0.5$ ) with the $y / D$ at various $D R$ s of the spirally semicircle-grooved tube. As the figure, it is found that the $D R=0.08$ and 0.1 give a better mixing of the fluid flow than the other cases when considered at the middle of the plane (in range $y / D=0.2-0.8$ ).

The temperature distributions on the tube wall of the spirally semicircle-grooved tube at various $D R$ s are illustrated in Fig. $11 \mathrm{a}-\mathrm{e}$, respectively, for $D R=0.02,0.04$, $0.06,0.08$, and 0.1 at $P R=1.4$ and $R e=5000$. A similar trend of the heat transfer characteristic, as depicted in Fig. 9, is found. It is interesting to note that the edges of the groove provide terrible heat transfer rate for all $D R s$.

The local Nusselt number distributions on the tube wall of the spirally semicircle-grooved tube are depicted in Fig. 12a-e for $D R=0.02,0.04,0.06,0.08$, and 0.1, respectively, at $R e=5000$ and $P R=1.4$. It is clearly seen in the figures that the $D R=0.02$ gives the lowest heat transfer rate. The heat transfer rate increases when increasing the depth of the semicircle groove on the tube wall due to the intensity of the swirling flow, especially, secondary swirling flow.

\section{Thermal performance evaluation}

The performance assessments of the spirally semicirclegrooved tube are reported in terms of the Nusselt number ratio $\left(N u / N u_{0}\right)$, friction factor ratio $\left(f / f_{0}\right)$, and thermal enhancement factor (TEF). The influences of the $D R$ and $P R$ on heat transfer, friction loss, and thermal performance are considered.

The variations of the $\mathrm{Nu} / \mathrm{Nu}_{0}$ with the $R e$ at various $P R$ and $D R$ values are presented in Fig. 13. In general, the $N u / N u_{0}$ slightly decreases when increasing the Reynolds number for all cases. At similar $P R$, the $D R=$ 0.1 provides the highest heat transfer rate, while the $D R$ $=0.02$ performs the lowest values. The increasing $D R$ leads to enhancing the Nusselt number. In addition, the $N u / N u_{0}$ of $D R=0.08$ and 0.1 is very close for all $P R$ s. The reduction of the $P R$ leads to increasing heat transfer rate. The spirally semicircle-grooved tube with $P R=0.6$ gives the highest heat transfer rate. The $N u / N u_{0}$ has no change when increasing $P R$ of the spirally semicircle-
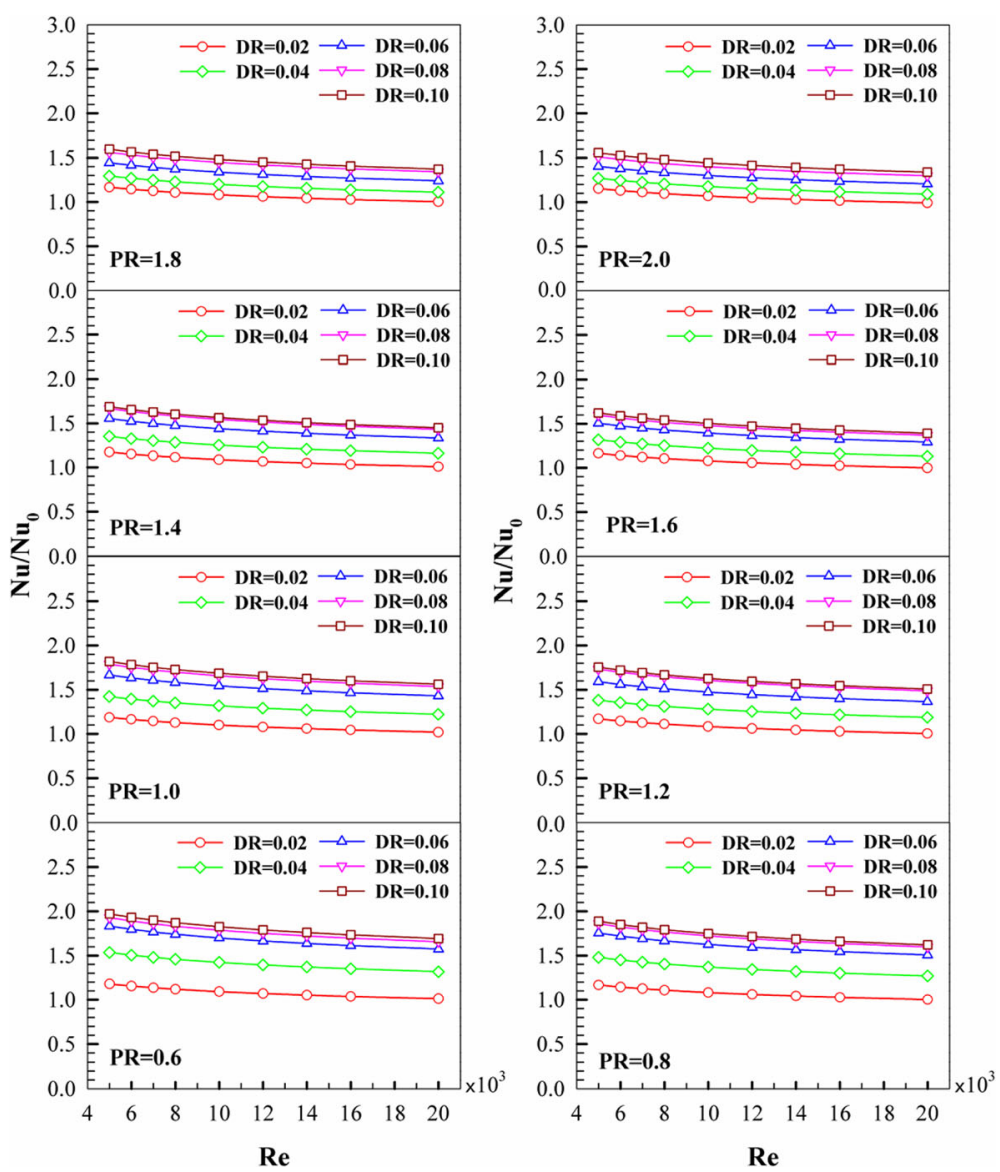

Fig. 13 The relation between $N u / N u_{0}$ and $D R$ 
grooved tube from 1.6 to 2.0. In range investigates, the $N u / N u_{0}$ for the spirally semicircle-grooved tube is around 1.16-1.96 depended on $D R, P R$, and $R e$.

The relations of the $f / f_{0}$ with the Reynolds number at various $P R$ and $D R$ values are reported in Fig. 14. Generally, the spirally semicircle-grooved tube has higher friction loss than the smooth circular tube in all cases. The $f / f_{0}$ slightly decreases when increasing the Reynolds number. The $D R=0.1$ provides the highest friction loss, while the $D R=0.02$ offers the lowest values of the pressure loss when considered at similar $P R$. The groove depth is the main cause for the augmentation of the pressure loss in the tube heat exchanger. The reduction of the $P R$ can help to reduce the pressure loss in the test tube. The spirally semicircle-grooved tube with $P R=1.8$ and 2.0 gives very close values of the friction factor ratio. The $f / f_{0}$ of the spirally semicircle-grooved tube is around $1.20-10.80$ depending on $D R, P R$ and $R e$.

The plots of the thermal enhancement factor with the Reynolds number with various $P R$ s and $D R$ s are plotted in Fig. 15. The TEF of the smooth circular tube is equal to 1 ; therefore, the advantage of the spirally semicircle-grooved tube should give the TEF higher than 1. In general, the TEF decrease with increasing the Reynolds number in all cases. Almost all cases of the spirally semicircle-grooved tube with $P R=0.6$ perform the TEF lower than 1 due to the pressure loss of the heating tube increases much more than the enhancement of the heat transfer rate when measured at similar pumping power. The maximum TEF is found at $D R=0.04$ for $P R=0.6-1.2$, while found at $D R=$ 0.06 for $P R=1.4-2.0$. The computational result reveals that the optimum TEF is around 1.11.

The variations of the $N u / N u_{0}, f l f_{0}$, and TEF with the $D R$ at various $P R$ values are created in Figs. 16, 17 and 18 , respectively. The increasing $D R$ and decreasing $P R$ lead to augmentations on both heat transfer rate and friction loss in the test tube. The optimum case, which gives the highest thermal performance around 1.11, is found at $D R=0.06$ and $P R=1.4$ when considered at the lowest Reynolds number, $R e=5000$.

\section{Correlation of the Nusselt number and friction loss}

The correlations of the Nusselt number and friction factor at $P R=1.4, R e=5000-20,000$, and $D R=0.02-0.10$
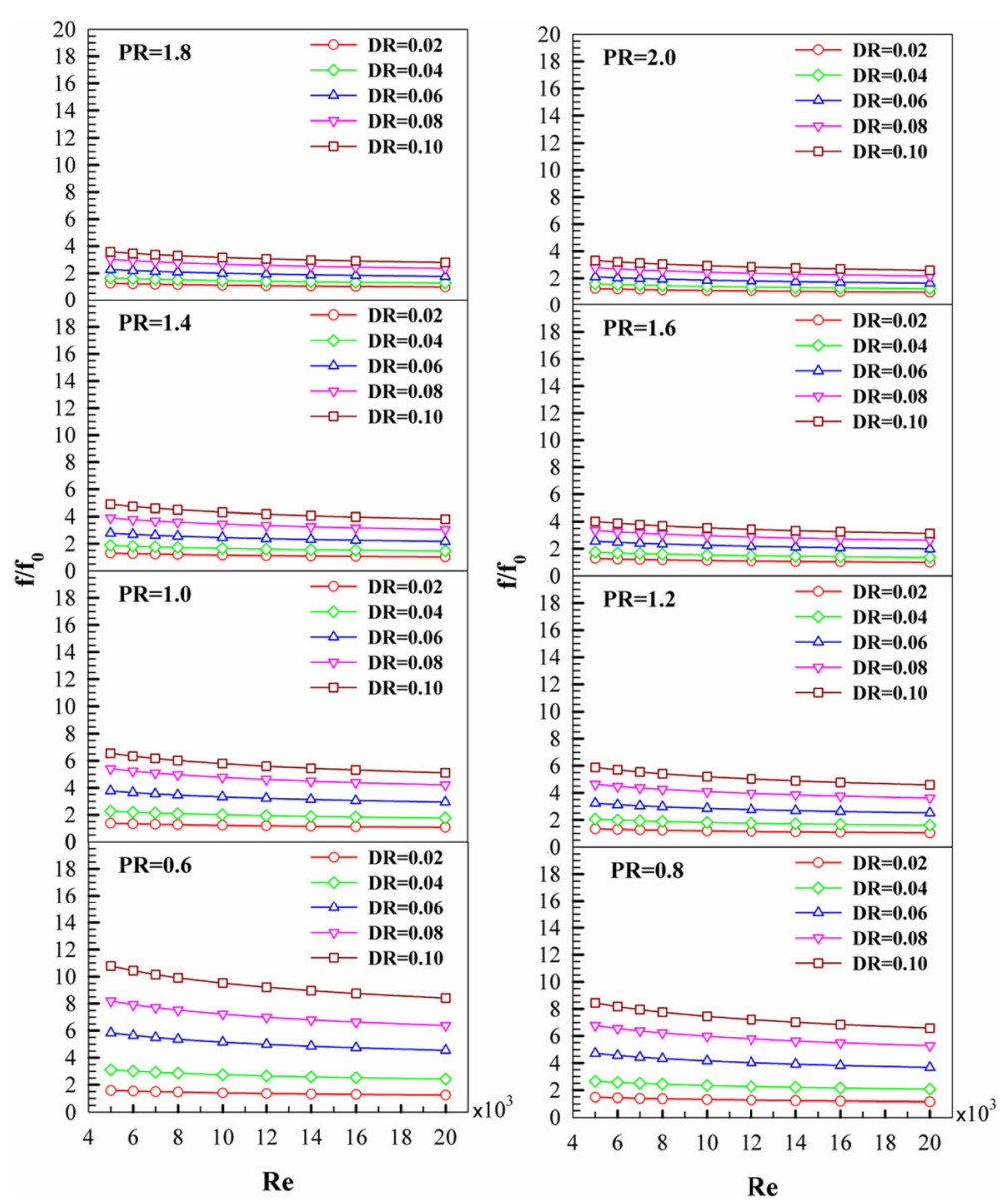

Fig. 14 The relation between $f / f_{0}$ and $D R$ 

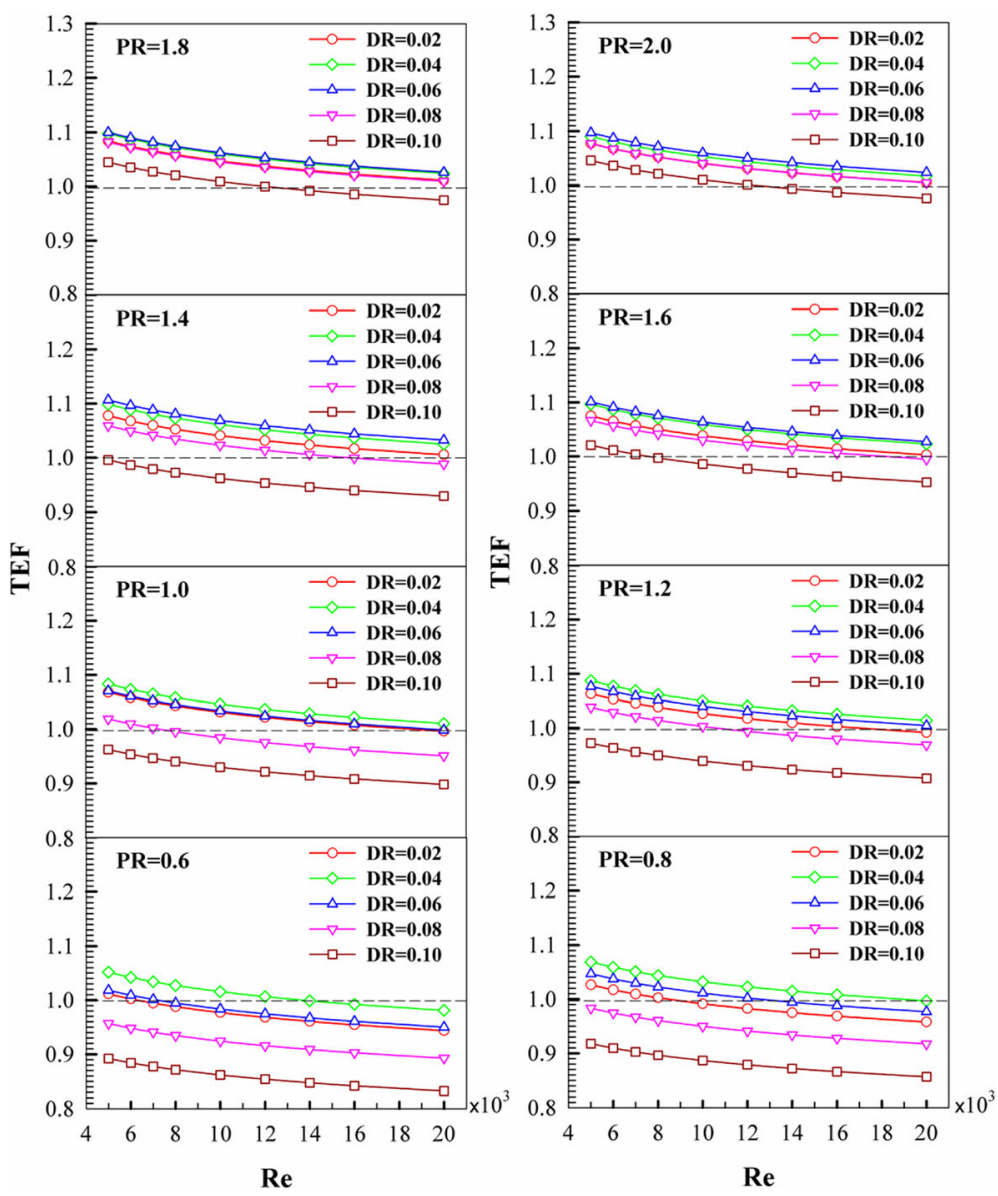

Fig. 15 The relation between TEF and DR
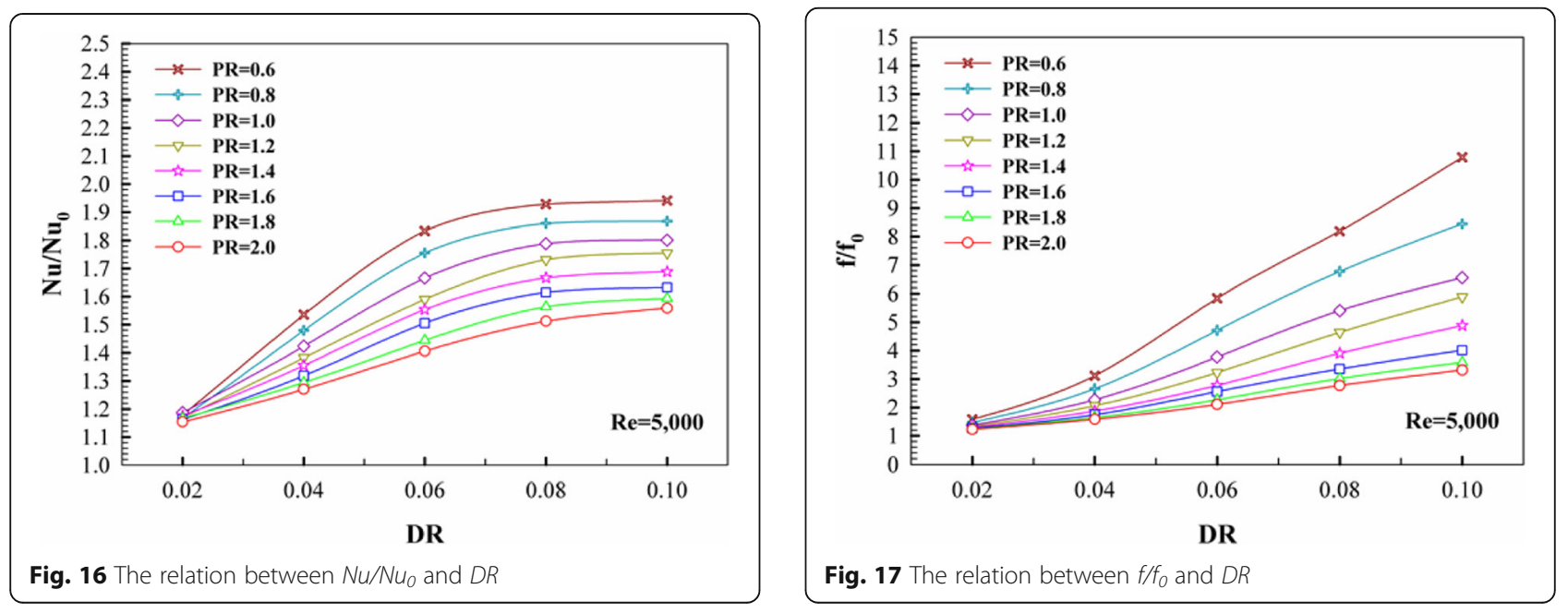


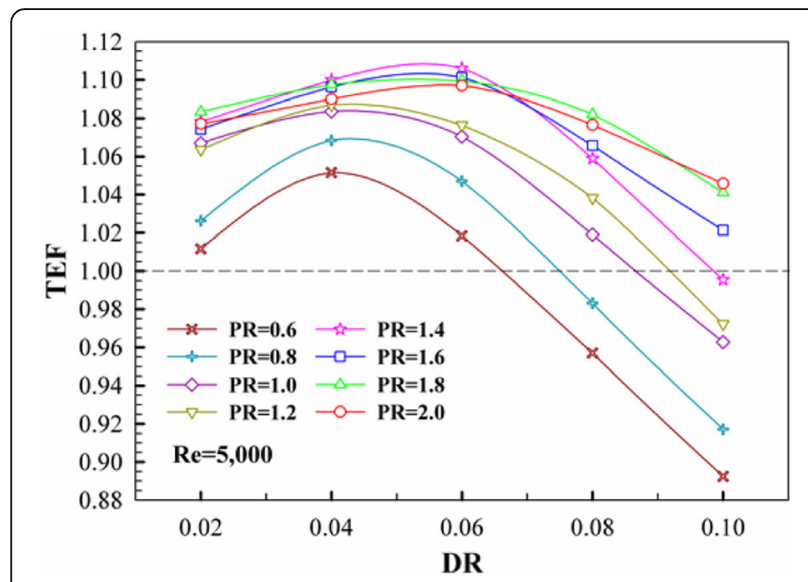

Fig. 18 The relation between $T E F$ and $D R$ are created. The correlations are separated into two parts: $D R \leq 0.06$ (uptrend of TEF) and $D R \geq 0.06$ (downtrend of TEF) as shown in the Fig. 19.

For $D R \leq 0.06$,

$$
\begin{aligned}
& N u=0.411 \operatorname{Re}^{0.614} \operatorname{Pr}^{0.4} D R^{0.249} \\
& f=30.568 \operatorname{Re}^{-0.43} D R^{0.674}
\end{aligned}
$$

For $D R \geq 0.06$,

$$
\begin{aligned}
& N u=0.333 \operatorname{Re}^{0.614} \operatorname{Pr}^{0.4} D R^{0.166} \\
& f=111.788 \operatorname{Re}^{-0.43} D R^{1.11}
\end{aligned}
$$

The deviations of the $N u$ and $f$ between numerical data and correlation data are within 1.8 and $6 \%$, respectively, for uptrend, and within 1.5 and $1.5 \%$ for downtrend, respectively.
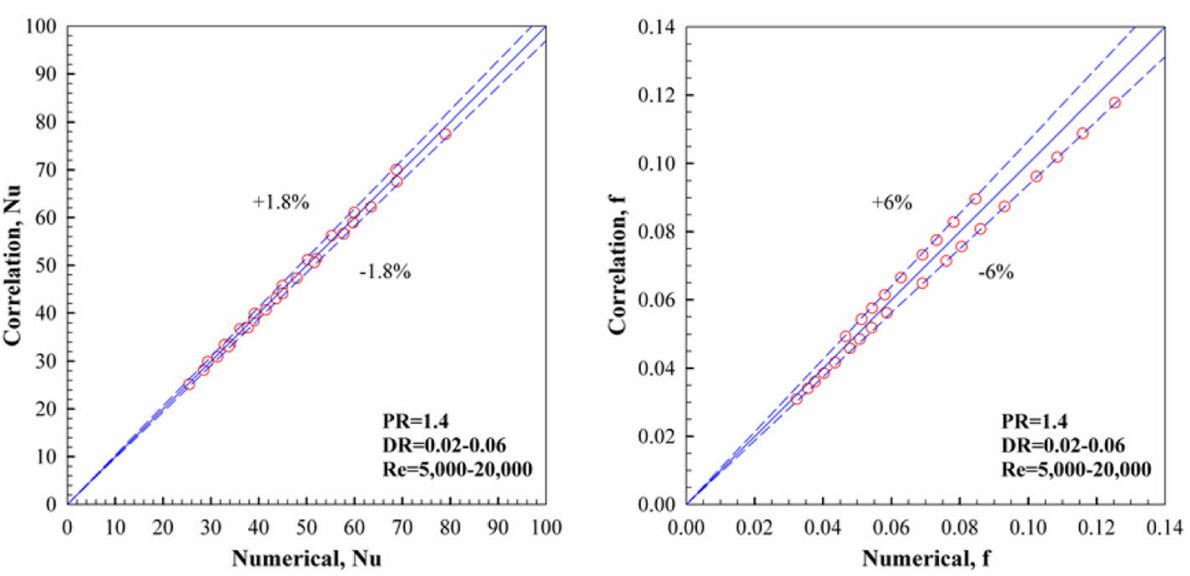

$\mathbf{a}$

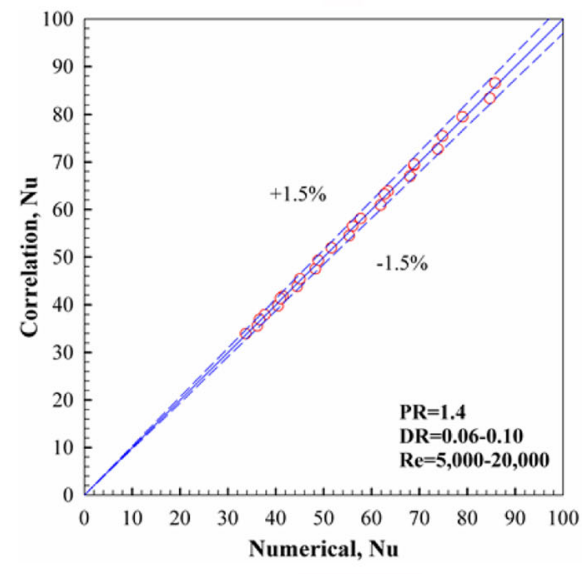

b

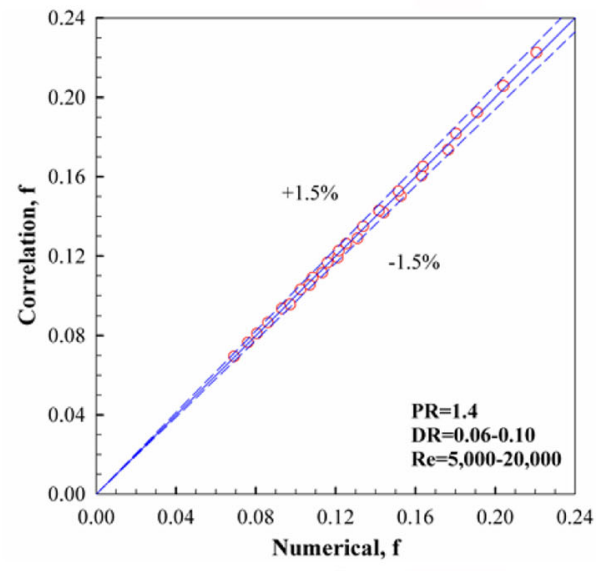

d

Fig. 19 The correlations of $\mathbf{a}$ Nusselt number and $\mathbf{b}$ friction factor with numerical result for $D R=0.02-0.06$ and $\mathbf{c}$ Nusselt number and $\mathbf{d}$ friction factor with numerical result for $D R=0.06-0.10$ at $P R=1.4$ and $R e=5000-20,000$ 


\section{Conclusions}

The numerical investigations on turbulent forced convection, heat transfer characteristic, and performance assessment in the spirally semicircle-grooved tube are examined. The influences of the groove depth and groove pitch for the spirally semicircle-grooved tube are investigated for the Reynolds number, $R e=5000-20,000$. The flow visualization and heat transfer behavior in the spirally semicirclegrooved tube are described. The major findings for the present investigation are concluded as follows.

The semicircle groove on the tube surface can produce the swirling flow through the test section. The swirling flow can separate into two types: main and secondary swirling flows. The main swirling flow is found in all $D R \mathrm{~s}$, while the secondary swirling flow is detected at $D R \geq 0.06$. The swirling flow disturbs the thermal boundary layer near the tube wall that is reason for heat transfer augmentation. The intensity or strength of the swirling flow depended on $D R$ and $P R$ of the groove. The increasing $D R$ and reducing $P R$ lead to augmenting strength of the flow that helps to increase heat transfer rate in the test section.

In the range examined, the augmentations on the Nusselt number and friction loss are around 1.16-1.96 and 1.2-10.8 times above the smooth tube. The optimum TEF around 1.11 is detected at $D R=0.06$ and $P R=1.4$ and $R e=5000$.

\section{Nomenclature}

$D$ characteristic diameter of semicircle-grooved tube, $\mathrm{m}$

$D R$ semicircle-grooved depth ratio, $(d / D)$

$P R$ semicircle-grooved pitch ratio, $(p / D)$

$d$ semicircle-grooved depth, $\mathrm{m}$

$p$ semicircle-grooved pitch, $\mathrm{m}$

$f$ friction factor

$h$ convective heat transfer coefficient, $\mathrm{W} \mathrm{m}{ }^{-2} \mathrm{~K}^{-1}$

$k$ turbulent kinetic energy, $\left(k=\frac{1}{2} \overline{u_{i}^{\prime} u_{j}^{\prime}}\right)$

$k_{\mathrm{a}}$ thermal conductivity of air, $\mathrm{W} \mathrm{m}{ }^{-1} \mathrm{~K}^{-1}$

$\mathrm{Nu}$ Nusselt number

$P$ static pressure, $\mathrm{Pa}$

Pr Prandtl number

Re Reynolds number, $\left(\rho u_{0} D / \mu\right)$

$T$ temperature, $\mathrm{K}$

TEF thermal performance enhancement factor, $(\mathrm{Nu} /$ $\left.N u_{0}\right) /\left(f / f_{0}\right)^{1 / 3}$

$u_{\mathrm{i}}$ velocity component in $\mathrm{x}_{\mathrm{i}}$-direction, $\mathrm{m} \mathrm{s}^{-1}$

$u_{\mathrm{i}^{\prime}}$ fluctuation velocity in $\mathrm{x}_{\mathrm{i}}$-direction, $\mathrm{m} \mathrm{s}^{-1}$

$u_{0}$ mean or uniform velocity in smooth tube, $\mathrm{m} \mathrm{s}^{-1}$

$x$ coordinate direction

\section{Greek letter}

$\mu$ dynamic viscosity, $\mathrm{kg} \mathrm{s}^{-1} \mathrm{~m}^{-1}$

$\Gamma$ thermal diffusivity

$\varepsilon$ dissipation rate

$\rho$ density, $\mathrm{kg} \mathrm{m}^{-3}$

\section{Subscript}

0 smooth tube

pp pumping power

\section{Acknowledgements}

The funding of this study is supported by King Mongkut's Institute of technology Ladkrabang research fund, Thailand. The researchers would like to thank Assoc. Prof. Dr. Pongjet Promvonge for suggestions.

\section{Authors' contributions}

PP conducted experiments and collected the data. AB and WJ wrote the paper and presented discussion. All authors read and approved the final manuscript.

\section{Competing interests}

The authors declare that they have no competing interests.

\section{Author details}

${ }^{1}$ Department of Mechanical Engineering, Faculty of Engineering, King Mongkut's Institute of Technology Ladkrabang, Bangkok 10520, Thailand. ${ }^{2}$ Department of Mechanical Engineering Technology, College of Industrial Technology, King Mongkut's University of Technology North Bangkok, Bangkok 10800, Thailand.

Received: 11 June 2016 Accepted: 20 October 2016

Published online: 27 October 2016

\section{References}

Al-Shamani, A. N., Sopian, K., Mohammed, H. A., Mat, S., Ruslan, M. H., \& Abed, A. M. (2015). Enhancement heat transfer characteristics in the channel with Trapezodial rib-groove using nanofluids. Case Studies in Thermal Engineering, 5, 48-58.

Aroonrat, K., \& Wongwises, S. (2011). Evaporation heat transfer and friction characteristics of R-134a flowing downward in a vertical corrugated tube. Experimental Thermal and Fluid Science, 35, 20-28.

Aroonrat, K., Jumpholkul, C., Leelaprachakul, R., Dalkilic, A. S., Mahian, O., \& Wongwises, S. (2013). Heat transfer and single-phase flow in internally grooved tubes. International Communications in Heat and Mass Transfer, 42, 62-68.

Chen, C., Wu, Y. T., Wang, S. T., \& Ma, C. F. (2013). Experimental investigation on enhanced heat transfer in transversally corrugated tube with molten salt. Experimental Thermal and Fluid Science, 47, 108-116.

Cheng, L., \& Chen, T. (2007). Study of vapor liquid two-phase frictional pressure drop in a vertical heated spirally internally ribbed tube. Chemical Engineering Science, 62, 783-792.

Dizaji, H. S., Jafarmader, S., \& Mobadersani, F. (2015). Experimental studies on heat transfer and pressure drop characteristics for new arrangements of corrugated tubes in a double pipe heat exchanger. International Journal of Thermal Sciences, 96, 211-220.

Dong, Y., Huixiong, L., \& Tingkuan, C. (2001). Pressure drop, heat transfer and performance of single-phase turbulent flow in spirally corrugated tubes. Experimental Thermal and Fluid Science, 24, 131-138.

Graham, D., Chato, J. C., \& Newell, T. A. (1999). Heat transfer and pressure drop during condensation of refrigerant 134a in an axially grooved tube. International Journal of Heat and Mass Transfer, 42, 1935-1944.

Hwang, K., Jeong, J., Hyun, S., Saito, K., Kawai, S., Inagaki, K., \& Ozawa, R. (2003). Heat transfer and pressure drop characteristics of enhanced titanium tubes. Desalination, 159, 33-41.

Incropera, F., \& Dewitt, P. D. (2006). Introduction to heat transfer (3rd ed.) Hoboken: Wiley.

Khoeini, D., Akhavan-Behabadi, M. A., \& Saboonchi, A. (2012). Experimental study of condensation heat transfer of R-134a flow in corrugated tubes with different inclinations. International Communications in Heat and Mass Transfer, 39, 138-143.

Laohalertdecha, S., \& Wongwises, S. (2010). The effect of corrugation pitch and the condensation heat transfer coefficient and pressure drop of R-134a inside horizontal corrugated tube. International Journal of Heat and Mass Transfer, 53, 2924-2931.

Launder, B. E., \& Spalding, D. B. (1974). The numerical computation of turbulent flows. Computer Methods in Applied Mechanics and Engineering, 3, 269-289.

Liu, L., Ling, X., \& Peng, H. (2013). Analysis on flow and heat transfer characteristics of EGR helical baffled cooler with spiral corrugated tubes. Experimental Thermal and Fluid Science, 44, 275-284. 
Liu, J., Xie, G., \& Simon, T. W. (2015). Turbulent flow and heat transfer enhancement in rectangular channels with novel cylindrical grooves. International Journal of Heat and Mass Transfer, 81, 563-577.

Lu, J. F., Shen, X. Y., Ding, J., \& Yang, J. P. (2013). Transition and turbulent convective heat transfer of molten salt in spirally grooved tube. Experimental Thermal and Fluid Science, 47, 180-185.

Lu, J. F., Shen, X. Y., Ding, J., Peng, Q., \& Wen, Y. L. (2013). Convective heat transfer of high temperature molten salt in transversely grooved tube. Applied Thermal Engineering, 61, 157-162.

Patankar, S. V. (1980). Numerical heat transfer and fluid flow. New York: McGraw-Hill. Tang, Y., Chi, Y., Chen, J. C., Deng, X. X., Liu, L., Liu, X. K., \& Wan, Z. P. (2007). Experimental study of oil-filled high-speed spin forming micro-groove fin-inside tubes. International Journal of Machine Tools and Manufacture, 47, 1059-1068.

Wang, L., Suna, D. W. Liang, P., Zhuang, L., \& Tan, Y. (2000). Heat transfer characteristics of carbon steel spirally fluted tube for high pressure preheaters. Energy Conversion and Management, 41, 993-1005.

Webb, R. L. (2009). Single-phase heat transfer, friction, and fouling characteristics of three-dimensional cone roughness in tube flow. International Journal of Heat and Mass Transfer, 52, 2624-2631.

Zhang, Q., Li, H., Zhang, W., Li, L., \& Lei, X. (2015). Experimental study on heat transfer to the supercritical water upward flow in a vertical tube with internal helical ribs. International Journal of Heat and Mass Transfer, 89, 1044-1053.

Zhang, X., Zhang, J., Ji, H., \& Zhao, D. (2015). Heat transfer enhancement and pressure drop performance for R417A flow boiling in internally grooved tubes. Energy, 86, $446-454$.

\section{Submit your manuscript to a SpringerOpen ${ }^{\circ}$ journal and benefit from:}

- Convenient online submission

- Rigorous peer review

- Immediate publication on acceptance

- Open access: articles freely available online

High visibility within the field

Retaining the copyright to your article

Submit your next manuscript at $\boldsymbol{s p r i n g e r o p e n . c o m ~}$ 